\title{
Influence of Strontium on the Physical, Mechanical and In-Vitro Bioactivity of Glass Ionomer Cements
}

\author{
Yiyu Li*
}

Department of General Dentistry, Peking University, Beijing, 100081

* Corresponding author email: yiyuli89@gmail.com

Received: 21 November 2019 / Revised: 29 December 2019 / Accepted: 31 December 2019 / Published: 31 December 2019

\begin{abstract}
In this work, we investigated the effects of strontium incorporation in the glass phase of glass ionomer cements (GIC). Three different glass compositions were synthesized with 0, 5, and $10 \mathrm{~mol} \%$ of $\mathrm{SrO}$ addition. GICs were prepared by the addition of $50 \mathrm{wt} \%$ polyacrylic acid (PAA) at powder to liquid ratio of 1:1.5. Initial characterization on the cement series was to study their rheological behavior. Cements represented working times between 50-64 seconds and setting times of 356-452 seconds. Rheological results indicated that the addition of strontium decreases the working and setting times of the cements. To analyze the mechanical properties, compressive and flexural strength studies were performed after 1, 10, and 30 days incubation in simulated body fluid (SBF). The compressive strength of the cements increased as a function of incubation time, with the strontium containing compositions showing the highest strength at 34 megapascal (MPa) and after 30 days of incubation. Biaxial flexural strength of the cements was not significantly affected by the composition and maturation time and ranged between 13.4 to $16.3 \mathrm{MPa}$. In-vitro bioactivity of the cements was analyzed using SBF trials and after 1, 10, and 30 days incubation periods. Strontium containing cements, showed higher solubility with higher amounts of calcium phosphate surface depositions only after 10 days incubation. The elemental identifications of the surface depositions indicated high amounts of $\mathrm{Ca}, \mathrm{P}$ and $\mathrm{Zn}$ are present on the surface of SBF incubated samples.
\end{abstract}

Keywords: GIC, Strontium, Compressive Strength, Flexural Strength, SBF, In-vitro

\section{Introduction}

The development of dental adhesives for restorative dentistry originated with the work of Bouncier in the 1950s, in trials of bonding resin to etched enamel[1]. Since then, different compositions of chemically adhesive materials have been developed with the introduction of zinc polycarboxylate cement (ZPC) and glass ionomer cements (GICs) in the late 1960s [2]. GICs were initially developed by Wilson and Kent as restoratives for dental applications in the 1970s[3]. The original GICs were water-based materials that set by an acid-base reaction. Further modifications of the chemical composition of these types of cements by Wilson and McLean, improved their physical properties [4]. Since their initial introduction, they have found versatile applications in the clinical dentistry such as linings, luting, and aesthetic restorations. GICs are hybrids of the polycarboxylate and silicate cements, with properties of both silicate cements such as translucency and fluoride release, and characteristics of polycarboxylate cements such chemical bond to tooth[5, 6]. GICs all contain a silicate-based glass phase and a polymer base in the form of an acid such as polyacrylic or tartaric acid and water. The first commercial GIC consisted of an aluminosilicate glass and an aqueous solution of polyacrylic acid [7].

Since the discovery of the GICs and their clinical use in dentistry, no significant adverse reaction has been reported [8]. In dental applications, the beneficial effects of GICs include adhesion to tooth mineral and release of fluoride ions that are thought to confer resistance against dental 
caries[9]. Also, freshly mixed GICs can chemically bond to both bone tissue and metal surfaces, which is beneficial in the sense that they do not rely solely on mechanical interaction to achieve fixation of a cement or implant to bone[10]. Conventional GICs adhere to untreated enamel and dentine, bone and base metals. Some GICs exhibit osteoconductive properties after implantation into bone[11]. Due to their superior biocompatibility, their capacity to adhere to surgical metals and chemically bond to the skeletal tissue, and also due to their unique setting reaction without heat generation and volumetric shrinkage, much attention has been focused on the development of GICs for use as bone cements[12, 13].

The setting reaction that occurs in all GICs is based on an acid-base reaction[12]. A hydrous polycarboxylic acid solution, conventionally PAA, reacts with an ion-releasing glass structure, which degrades to form a hydrogel or polysalt matrix[14]. The acid attacks the surface of the glass particles, which leads to surface degradation of the glass particles and release of metallic cations into the solution. The metallic cations, such as $\mathrm{Ca}^{2+}$, crosslink with the carboxylate groups of polyacrylate chains resulting in the formation of hard cement[15]. The resulting set cement consists of unreacted glass particles that have been embedded in a polysalt matrix[15].

The chemistry of the glass composition significantly affects the properties of the resultant cement composition[16]. The reactivity of the glass phase depends on the structure of the glass, the number of modifying cations, their valency and then on their acidity/basicity[17]. Inclusion of network modifiers such as $\mathrm{Sr}^{2+}$ can increase the number of non-bridging oxygens and make the glass network disrupted[18, 19]. This modified glass structure is susceptible to acid attack, which is an important property in degradable glasses. Strontium in the body behaves in a very similar fashion to $\mathrm{Ca}$, where it is mostly accumulated in skeletal tissue[20, 21]. Research by $\mathrm{Hao}$ et al investigated the substitution of $\mathrm{Ca}$ by $\mathrm{Sr}$ into hydroxyapatite, as $\mathrm{Sr}$ is one of the divalent ions that can replace $\mathrm{Ca}[22]$. Their study demonstrated that Sr can participate effectively in the re-mineralization process of the bone[22]. Another study by Tripathi et al have shown that the released $\mathrm{Sr}$ ions from glass structure can show anti-cariogenic properties [23]. The main goal of this study is to investigate how Sr incorporation can affect the properties of the GICs. In this study, we have incorporated $\mathrm{SrO}$ in the glass chemistry and evaluated the physical, mechanical and biological behavior of the resultant cements.

\section{Materials \& Methods}

\subsection{Glass Synthesis}

To prepare the glass powders, three novel glass compositions were synthesized using the traditional melt-quench method. A silicate-based control glass, and two strontium-containing glass compositions were synthesized. Detailed compositions of the synthesized glass powders in $\mathrm{mol} \%$ are presented in Table 1 . To prepare the glass compositions, the analytical grades of reagents $\left(\mathrm{SiO}_{2}, \mathrm{CaCO}_{3}, \mathrm{ZnO}, \mathrm{SrCO}_{3}\right.$, and $\left.\mathrm{P}_{2} \mathrm{O}_{5}\right)$ were weighted and mixed for 30 minutes to homogenize the batch of the different reagent powders. Then the glass batch was poured in a platinum crucible and oven-dried at $110^{\circ} \mathrm{C}$ for 2 hours to eliminate any atmospheric water absorbed. The oven-dried glass batch was melted in a platinum crucible at $1360^{\circ} \mathrm{C}$ for 4 hours. The molten glass was then poured in cold water and removed immediately to obtain glass frits. The resulting frits were dried overnight and pulverized to glass powders with particle sizes of $\leq 45 \mu \mathrm{m}$.

Table 1: Glass compositions (Mol.\%).

\begin{tabular}{|cccccc|}
\hline & $\mathrm{SiO}_{2}$ & $\mathrm{CaO}$ & $\mathrm{ZnO}$ & $\mathrm{P}_{2} \mathrm{O}_{5}$ & $\mathrm{SrO}$ \\
\hline GS0 & 55 & 10 & 30 & 5 & 0 \\
\hline GS5 & 50 & 10 & 30 & 5 & 5 \\
\hline GS10 & 45 & 10 & 30 & 5 & 10 \\
\hline
\end{tabular}

\subsection{Glass Ionomer Cement Formulation}

Glass ionomer cements were prepared by hand mixing the synthesized glass powders, powdered polyacrylic acid (PAA) and deionized water on a glass slide. The formulation used for the cement making is presented in Table 2.

Table 2: Cement formulation.

\begin{tabular}{|cccc|}
\hline & Glass & PAA & Water \\
\hline P/L 1:1.5 & $1.00 \mathrm{~g}$ & $0.75 \mathrm{~g}$ & $0.75 \mathrm{ml}$ \\
\hline
\end{tabular}


Yiyu Li, J. Mod. Mater;; Vol. 6, Issue 1, pp: 30-39, 2019

For the cement preparation, $1 \mathrm{~g}$ of each glass powder was mixed with $0.75 \mathrm{~g}$ of PAA powder on a clean glass slide using a spatula. Once the glass and the acid powders were mixed thoroughly, $0.75 \mathrm{ml}$ of deionized water was added to the mixture and blended using the clean spatula until the cement mixture was prepared and ready for further processing.

\subsection{Working Time Measurements}

The working times of cements were determined using a stopwatch by measuring the time from the start of mixing to where the cement was no longer pliable. The setting time of the cements was tested following ISO9917 standard which defines the standard for timing the setting times of glass ionomer cements [24]. An empty mould was placed on aluminium foil and filled to a level surface with mixed cement. Sixty seconds after mixing, the entire assembly was placed on a metal block $(8 \mathrm{~mm} \times 75 \mathrm{~mm} \times 100 \mathrm{~mm})$ in an oven maintained at $37^{\circ} \mathrm{C}$. Ninety seconds after mixing, a Vicat needle indenter (mass, 400g) was lowered onto the surface of the cement. The needle was allowed to remain on the surface for five seconds, the indent was then observed, and the process repeated every thirty seconds until the needle failed to make a complete circular indent when viewed at $\mathrm{x} 2$ magnification. Each measurement was conducted on 5 samples to ensure reproducibility.

\subsection{Compressive Strength}

To evaluate the compressive strength, cements cylinders with dimensions of $15 \times 7 \mathrm{~mm}$ were prepared. Once the cements were set, they were transferred to simulated body fluid and were kept for 1,10 , and 30 days in an incubator at $37^{\circ} \mathrm{C}$. At the end of each incubation time period, the cements were tested for their compressive strength in a Universal Testing Machine at a crosshead speed of $1 \mathrm{~mm} / \mathrm{min}$.

\subsection{Biaxial Flexural Strength}

To measure the flexural strength of the cement series, disks with dimensions of $3 \times 10 \mathrm{~mm}$ were prepared. Biaxial flexural strength of the cements was measured following the formula and the method proposed by Mokhtari et al [6]. Briefly the set cement disks were kept in simulated body fluid for 1, 10, and 30 days prior to testing. The cement samples were tested on a biaxial flexural fixture, where the disks were loaded by a piston from above and supported by three balls from below. The measurements were performed on a Universal Testing Machine at a crosshead speed of $0.5 \mathrm{~mm} / \mathrm{min}$.

\subsection{In-Vitro Bioactivity Testing}

To study the in-vitro bioactivity of the cement samples, Simulated Body Fluid (SBF) solution was prepared. The reagents listed in Table 3 were dissolved in order, in $500 \mathrm{ml}$ of purified water (in the order listed) using a magnetic stirrer. The solution was then maintained at $36.5^{\circ} \mathrm{C}$ using a water bath. $1 \mathrm{~N}-\mathrm{HCl}$ was used to adjust the $\mathrm{pH}$ to 7.4. Purified water was used to adjust the total volume of liquid to 1 litre. SBF was stored in a refrigerator for a maximum of 3 days. Any SBF that formed precipitates after storage was discarded. Then cement disks with dimensions of $3 \times 10 \mathrm{~mm}$ were prepared. Then each specimen was immersed in $10 \mathrm{ml}$ of the SBF solution and stored in an incubator at $37^{\circ} \mathrm{C}$ for 1,10 , and 30 days. After the end of each incubation time period, specimens were removed from the solution and dried to be analyzed for the surface depositions with a scanning electron microscope (SEM).

Table 3: Reagent list for the preparation of SBF.

\begin{tabular}{|ccc|}
\hline Order & Reagent & Grams \\
\hline 1 & $\mathrm{NaCl}$ & 7.99 \\
\hline 2 & $\mathrm{NaHCO}_{3}$ & 0.35 \\
\hline 3 & $\mathrm{KCl}$ & 0.224 \\
\hline 4 & $\mathrm{~K}_{2} \mathrm{HPO}_{4} \cdot 3 \mathrm{H}_{2} \mathrm{O}$ & 0.228 \\
\hline 5 & $\mathrm{MgCl}_{2} \cdot 6 \mathrm{H}_{2} \mathrm{O}$ & 0.305 \\
\hline 6 & $1 \mathrm{M}-\mathrm{HCl}$ & $40 \mathrm{ml}$ \\
\hline 7 & $\mathrm{CaCl}_{2}$ & 0.278 \\
\hline 8 & $\mathrm{Na}_{2} \mathrm{SO}_{4}$ & 0.071 \\
\hline 9 & $\mathrm{NH}_{2} \mathrm{C}_{\left(\mathrm{CH}_{2} \mathrm{OH}\right)_{3}}$ & 6.057 \\
\hline
\end{tabular}

\subsection{Scanning Electron Microscopy}

Imaging of the SBF incubated samples was performed using scanning electron microscope SEM (Philips 30XLFEG, Netherlands) coupled with an Energy-dispersive X-ray spectroscopy 
Influence of Strontium on the Physical, Mechanical and In-Vitro Bioactivity of Glass Ionomer Cements

(EDX). Samples were gold coated for 30 seconds using a sputter coater

\section{Results \& Discussion}

This study investigates the physical and biological effects of strontium incorporation in the glass composition of glass ionomer cements. Three different glass compositions with varying amount $(0,5$ and $10 \mathrm{~mol} \%)$ of $\mathrm{SrO}$ were prepared. The glass compositions are presented in Table 1. Glass frits were pulverized to glass powders with particle sizes of less than $45 \mu \mathrm{m}$. Resultant glass powders were used to fabricate glass ionomer cements with the addition of polyacrylic acid (PAA) and DI water. The exact formulation of the GICs is presented in Table 2. The initial characterization on GICs was to perform rheological testing of working and setting times. The setting time (St) of these cements is determined according to ISO 9917 standard, however the working time (Wt) is not governed by any standard so the Wt was taken as the period of time where the cement retains sufficient viscosity for implantation. The Wt and St were performed on the GICs made from $50 \mathrm{wt} \% \mathrm{PAA}$ concentration and is represented in seconds in Figure 1. From Figure 1 it can be seen that there is a compositional dependence in the $\mathrm{Wt}$ and $\mathrm{St}$ of each of these cements with an increased $\mathrm{SrO}$ concentration in the glass. The longest Wt of the cement series was attributed to GS0 with a Wt of 64s while the shortest Wt was with GS10 at with a Wt of 50s. This may be attributed to the Sr ion

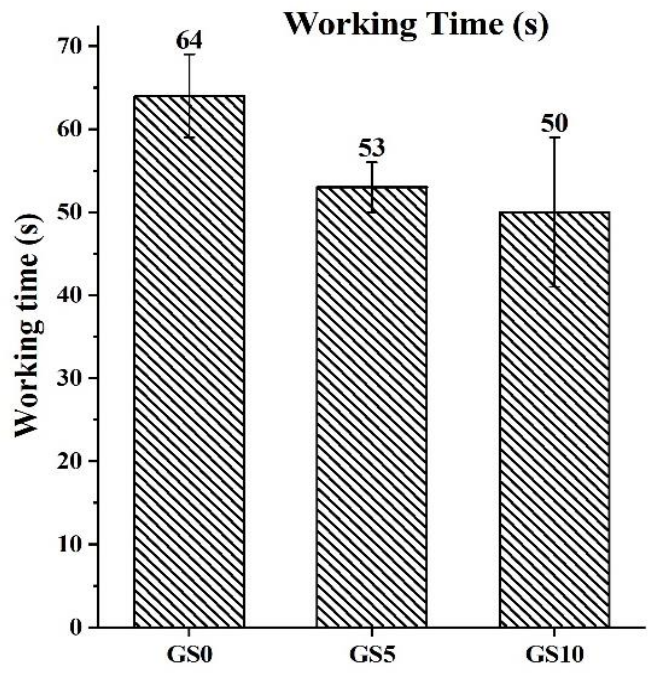

affecting the $\mathrm{pH}$ of the local environment of the cement mixture, hence resulting in a more rapid set. The setting times $(\mathrm{St})$ are determined in accordance to the standards defined for the setting times of dental GICs. Figure 1 shows the St of GS0, GS5, and GS10 at 50wt $\%$ PAA concentration. The St of the cement series shown in Figure 1 behaves in a similar fashion to the Wt. The longest St of the cement series was attributed to GS0 with a St of $452 \mathrm{~s}$, which corresponds to 7 minutes and 32 seconds. The shortest St was attributed to GC10 with a time of 356s which corresponds to 5 minutes and 56 seconds.

An ideal bone cement needs to have a prolonged Wt and should set rapidly. The Wt allows the surgeon/user time to sufficiently mix the material to a homogenous paste and to properly manipulate the material into place. The bone cement should ideally then set rapidly. A rapid set cement reduces open wound exposure during surgery. Dental GICs are structurally more closely related to the cements discussed here than the orthopaedic bone cements and have been quoted in the literature as having St between 2.25 - 6.5 minutes depending on the composition[1]. Cement series analyzed here exhibited St ranging between 7.32 to 5.56 minutes, which is close to the values reported for GICs. The Wt and St decreased by increasing the $\mathrm{SrO}$ content in the glass series. A possible explanation for the reduction in Wt and St could be due to the composition of the glass under investigation.

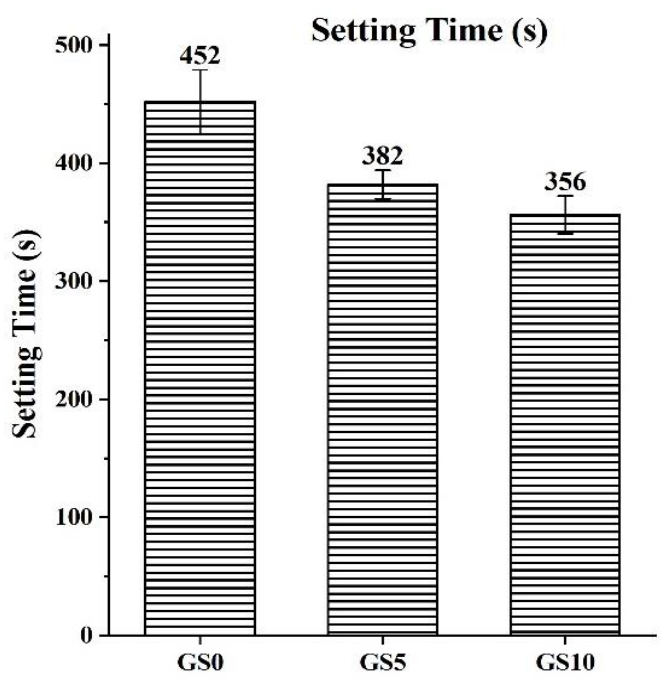

Figure 1: Working and Setting times of GSO, GS5, and GS10 cements. 


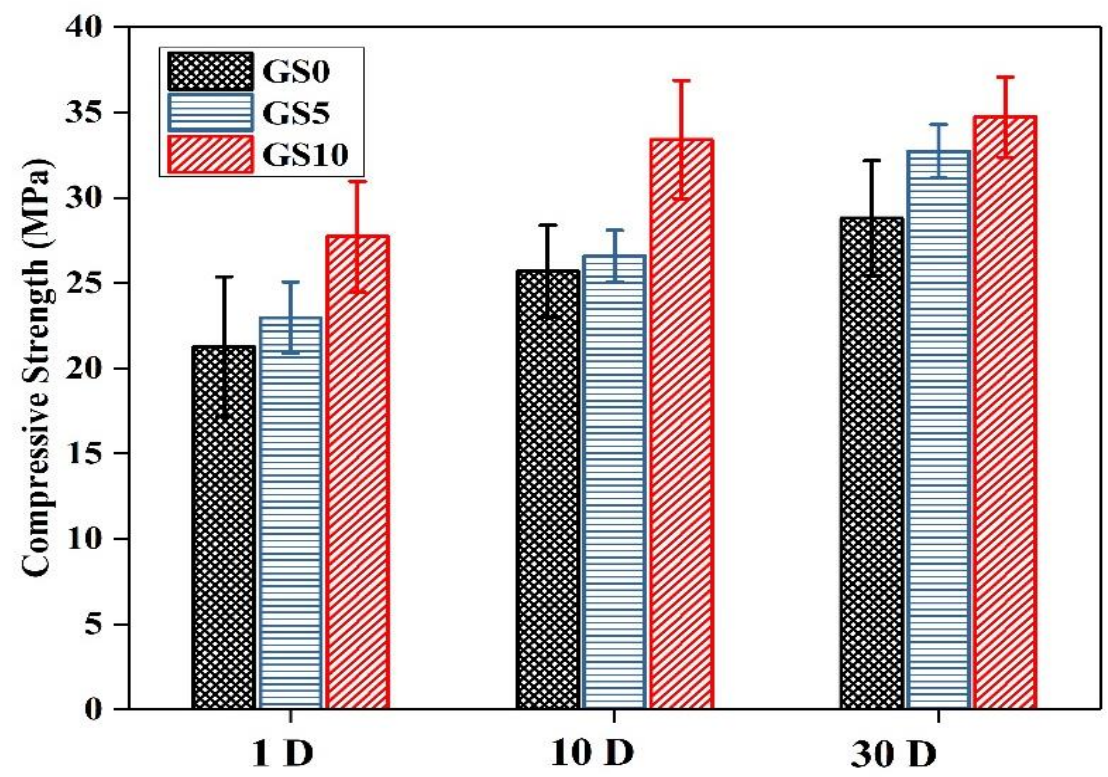

Figure 2: Compressive strength of GSO, GS5, and GS10 after 1, 10, and 30 days incubation in SBF.

Degradation of the glass toward the polyacrylic acid depends on the reactivity of the glass which is a great function of the glass chemistry and structure. Substitution of $\mathrm{SiO}_{2}$ for network modifiers, in this case $\mathrm{SrO}$, will disrupt the glass network and make it susceptible to acid attack[20]. As the glass particle is attacked by hydrogen ions from the PAA it starts to degrade and release metallic cations such as calcium, strontium, and silica in the surrounding media. The release of this metallic cations such as $\mathrm{Ca}^{2+}$, $\mathrm{Si}^{4+}$, and $\mathrm{Sr}^{2+}$ will increase the local $\mathrm{pH}$ of the solution [18]. As the $\mathrm{pH}$ rises, the PAA ionizes and creates an electrostatic field, which encourages the migration of the released cations into the aqueous phase. As the PAA ionizes further, the polymer chains unwind as the negative charges on them increases and the viscosity of the cement paste increases [12]. Therefore, the SrO substituted glasses will have faster degradation rates, and hence higher Wt and St compared to control glass with higher $\mathrm{SiO}_{2}$ content. To analyze the mechanical properties of the cements, compressive strength and biaxial flexural strength of the cements were analyzed over 1, 10 and 30 days incubation in simulated body fluids (SBF). Figure 2 shows the compressive strength of the cements in (MPa). After 1 day of incubation in SBF, the compressive strength of GS0, GS5, and GS10 was found to be at 21,25 , and $28 \mathrm{MPa}$, respectively. From Figure 2, it is evident that the compressive strength of the cements increases as a function of incubation time in the SBF. The highest compressive strength of all three compositions was found after 30 days of incubation period. The compressive strength of the cements after 30 days of incubation time was found to be at 27, 33, and $34 \mathrm{MPa}$ for GS0, GS5, and GS10, respectively. Figure 2 also demonstrates that there is a compositional dependence in the compressive strength of the cements at each time period, where GS0 shows the lowest and GS10 shows the highest strength respectively.

The strengthening process in GICs is known to occur due to a number of parameters. The molecular weight $(\mathrm{Mw})$ and concentration of PAA used can influence strength. This occurs due to the increase in COO- groups which facilitates an increase in crosslinking within the cement matrix between the PAA chain and the metal cations released from the glass[25]. This is due to the fact that the change in the local $\mathrm{pH}$ affected by the ion release from the glass particles highly affects the ionization of PAA, and further unwinding process of the $\mathrm{COO}$ groups on the acid chains [7]. The number of COO groups available in the crosslinking process, and the number of the released metallic cations in the solution defines the kinetics of the acid-base reaction in the set cement [11]. There is a 
Influence of Strontium on the Physical, Mechanical and In-Vitro Bioactivity of Glass Ionomer Cements

compositional difference between the control and $\mathrm{SrO}$ containing cements. The $\mathrm{Sr}^{2+}$ in the glass phase of these cements acts as a network modifier where it facilitates the degree of crosslinking as compared to control cements. This is in agreement with the rheological studies of these cements with faster rates of Wt and St of $\mathrm{SrO}$ containing cements. Higher degradation rates in the $\mathrm{SrO}$ containing glasses and the release of $\mathrm{Sr}$ ions in the water within the process of setting of the cements, increases the rate of gelation. Unwinding of the PAA chains, and increased concentration of metallic cations in the solution can lead to an increase crosslinking density between the PAA chains and released ion within the cement matrix, which subsequently can increase the strength of the cements. Similarly, the increase in the strength as a function of time can be explained by the process of maturation of these cements which is associated with an increase in the crosslinking density. It is reported that the setting reaction of the commercial GICs, which is considered as dissolution and then gelation, take place within the first 24 hours[26]. After the initial setting reaction and over time, cements start to mature which is considered as the third stage of setting. Over maturation of the cements additional crosslinking occurs where it can potentially lead to increase in the mechanical properties. As cements mature, the steady release of ions from the glass phase into the solution will crosslink with the remaining unreacted PAA chain and facilitate the formation of new calcium, strontium polyacrylates which increases the crosslinking density. To further analyze the mechanical properties, biaxial flexural strength studies were performed on the cement series.

Figure 3 shows the biaxial flexural strength of the cement series as incubated in the SBF for 1, 10, and 30 days. From Figure 3, it is evident that the incubation of the cements did not significantly change the flexural strength of the cements. This is opposite to the trend observed for the compressive strength. The flexural strength of the GSO was at 14.7, and 15.2 MPa after 1 and 30 days incubation time period, respectively. Similarly, for GS5 and GS10, the flexural strength was at 13.4 and $16.1 \mathrm{MPa}$ after 1 day, and 14.7 and 16.3 $\mathrm{MPa}$ after 30 days of incubation, respectively.

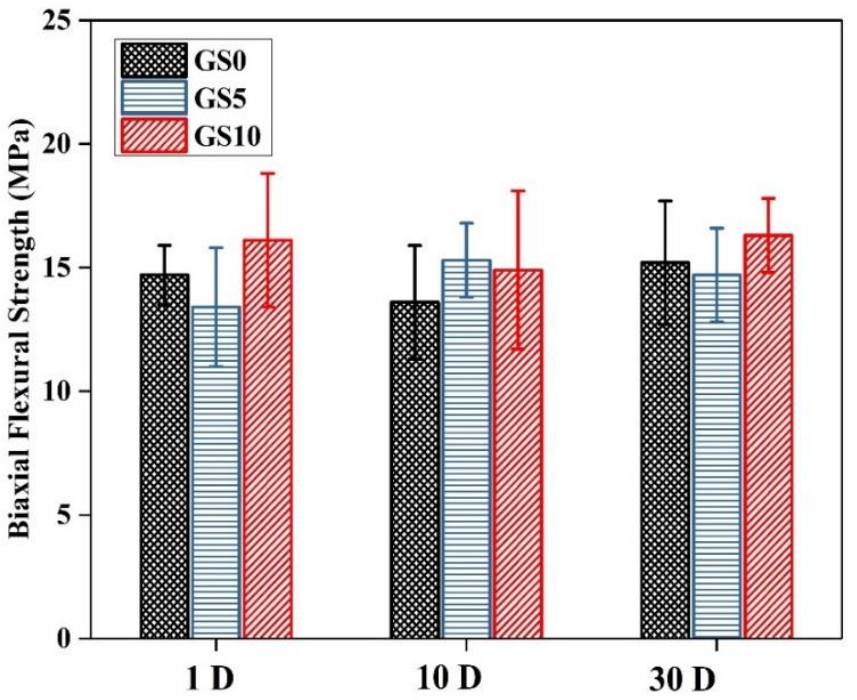

Figure 3: Biaxial Flexural strength of GSO, GS5, and GS10 after 1, 10, and 30 days incubation in $S B F$.

The results from Figure 3 indicate that the cements did not significantly change in the flexural strength during maturation process. The flexural strength test was originally developed for brittle ceramics however it is also suitable for brittle dental materials such as GICs. This material property tests the area of maximum tensile stresses which is located at the center of the lower face of the specimen. This is highly relevant as this test modality more accurately reflects the stresses present in a clinical situation, as bone typically fails in tension. Mokhtari et al also suggest that the measurement of strength in brittle materials under biaxial, rather than uniaxial conditions are often considered more reliable since edge failures (due to cement preparation) are eliminated [6].

The chemistry of the cements highly affects the compressive strength of the cements due to changes in the crosslinking density. However, in testing the flexural strength, internal defects such as voids and pores will significantly alter the flexural strength of the cements [27]. Overall the mechanical properties testing of the cements revealed that they have sufficient mechanical properties to be considered for dental and skeletal applications. In particular, the compressive strength of the cements increased with maturation time, with $\mathrm{SrO}$ containing 
Yiyu Li, J. Mod. Mater;; Vol. 6, Issue 1, pp: 30-39, 2019

cements having higher values compared to the control cement.

Another important characteristic that determines the lifespan of a biomaterial is the performance in the biological environment. A test that is widely accepted to determine a material's performance in close proximity to bone is the Simulated Body Fluid (SBF) trials. The formation of calcium phosphate (CaP) layer on the surface, when immersed in SBF, is a good indication of its bioactivity. The deposition of $\mathrm{CaP}$ layer on the surface facilitates the nucleation of biological apatite. This layer then promotes adsorption of proteins, cell attachment and eventually the formation of a strong bond with the hard tissue[28]. SBF trials were conducted on the series of cements and the results are presented and discussed further. Figure 4 shows the SEM micrographs of the cement series incubated in SBF for 1 day. As can be seen from Figure 4, none of the cement series exhibited surface depositions after 1 day. These images show the presence of unreacted glass particles embedded in the polymer matrix. Cracks in the surface of the cement are caused by dehydration; a result of preparing these samples for SEM. The Energydispersive X-ray spectroscopy (EDX) results for the control sample was found to contain only the reagents used to make the cement sample and is being used as a baseline to quantify how much calcium and phosphorus are present in the cement in comparison to the surface composition after immersion in SBF.

Figure 5 shows the surface of the SBF incubated samples after 10 days. Control cement showed the least surface depositions at this time period whereas GS10 represented the highest amounts of the percipients. The presence of depositions on the surface of GS5, and GS10 samples can be attributed to $\mathrm{CaP}$ depositions. It is evident that $\mathrm{CaP}$ clusters are forming although they are widely dispersed.
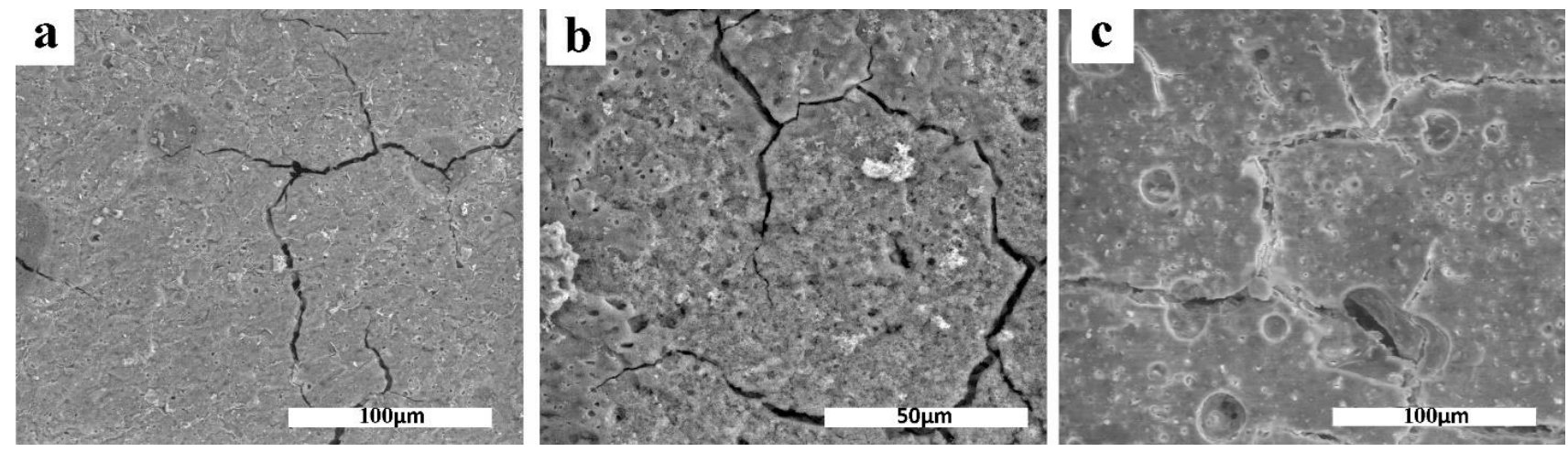

Figure 4: SEM images of a) GSO, b) GS5, and c) GS10 after 1-day incubation in SBF.
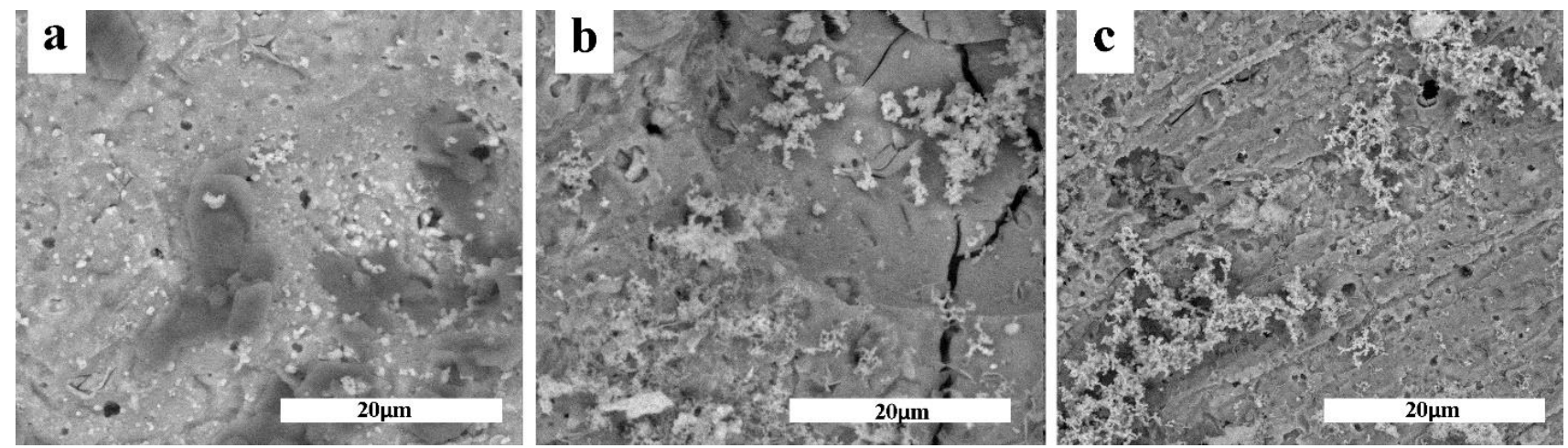

Figure 5: SEM images of a) GSO, b) GS5, and c) GS10 after 10-days incubation in SBF. 
Influence of Strontium on the Physical, Mechanical and In-Vitro Bioactivity of Glass Ionomer Cements

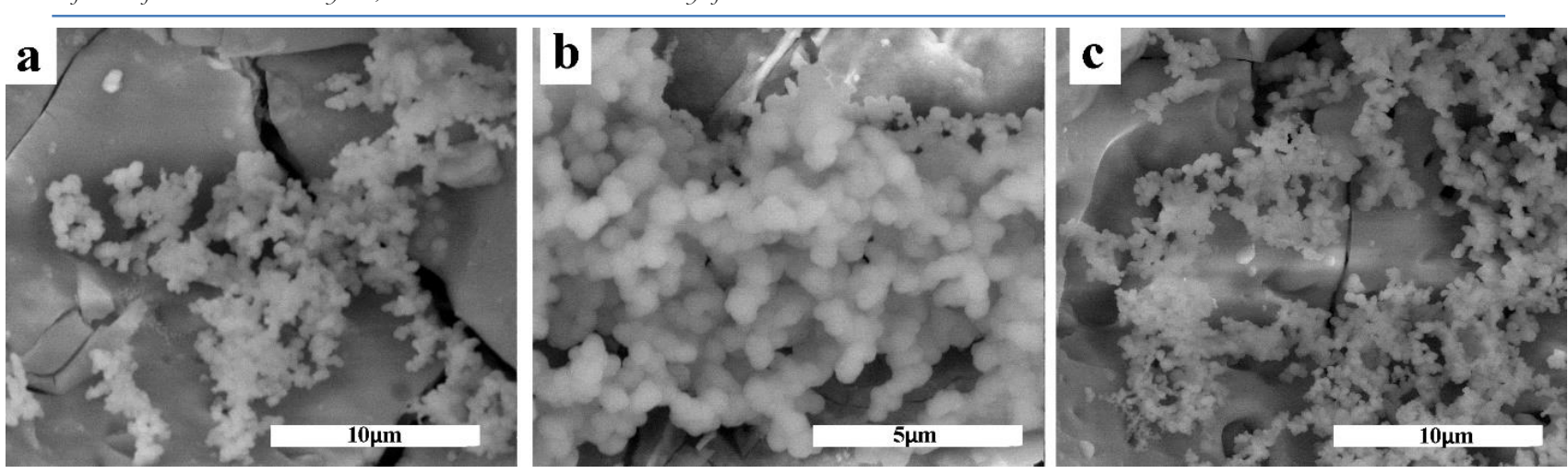

Figure 6: SEM images of a) GSO, b) GS5, and c) GS10 after 30-days incubation in SBF.

The elemental compositions of these precipitates were further analyzed by EDX. The surface depositions are increasing with respect to maturation time. After 30 days of incubation, surface of the all cement series is covered with the $\mathrm{CaP}$ precipitates as shown in Figure 6. The elemental compositions of the precipitates were analyzed using EDX, and results are presented in Figure 7. The EDX traces reveals the cement base materials $\mathrm{Si}, \mathrm{Zn}, \mathrm{Sr}$ and $\mathrm{Ca}$ of the cements along with high amount of $\mathrm{P}, \mathrm{Ca}$, and $\mathrm{Zn}$ at 23.1, 12.4 , and $49.7 \mathrm{wt} \%$.

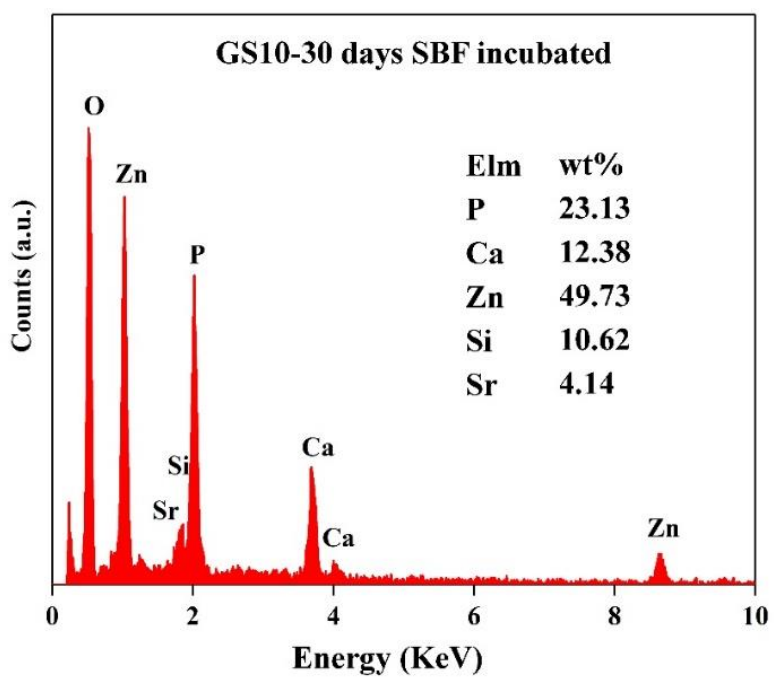

Figure 7: EDX analysis of the surface depositions on GS10 after 30 days incubation in SBF.

The In-Vitro bioactivity studies of novel GICs tested here show positive results when immersed in SBF. In particular, strontium containing cements, exhibited a higher amounts of $\mathrm{CaP}$ surface layer even after 10 days as identified by SEM. The main reason for the bioactivity of these GICs is the structure of the glass. It is known that precipitation of $\mathrm{CaP}$ is due to ion exchange between the cement and the surrounding solution [29]. The presence of network modifiers favors the ion exchange process by making the glass network disrupted. The incorporation of modifier ions in the silica matrix leads to a disruption of the glass network and formation of the non-bridging oxygen groups [29]. An increase in the number of nonbridging oxygen groups in the glass structure The disruption in the glass structure leads to a higher dissolution rate of the glass particles in the physiological solutions, which facilities the migration of $\mathrm{Ca}^{2+}$ and $\mathrm{PO}_{4}{ }^{3-}$ groups to the surface in order to form a $\mathrm{CaP}$ rich layer.

\section{Conclusions}

The substitution of $\mathrm{SrO}$ for $\mathrm{SiO}_{2}$ in the glass composition of the GICs was investigated in order to study the physical, mechanical and biological behavior of the resultant cements. Results from rheological behavior analysis indicated that the strontium incorporation reduced the working and the setting times of the cements. The addition of strontium resulted in a higher compressive strength of the cements as a result of higher crosslinking density. Bioactivity of the cements was analyzed using the SBF trials and after 1, 10, and 30 days. The presence of the CaP depositions was identified by SEM and EDX analysis. The positive results from the mechanical and biological behavior analysis of the strontium modified cements indicate their potential applications for skeletal tissue.

\section{Competing Interests}

The author declared that he does not have any potential conflict of interest regarding this publication. 
Yiyu Li, J. Mod. Mater;; Vol. 6, Issue 1, pp: 30-39, 2019

\section{How to Cite this Article:}

Y. Li, "Influence of Strontium on the Physical, Mechanical and In-Vitro Bioactivity of Glass Ionomer Cements", J. Mod. Mater., vol. 6, no. 1, pp. 30-39, Dec. 2019. doi:10.21467/jmm.6.1.30-39

\section{References}

[1] M. J. Tyas, and M. F. Burrow, "Adhesive restorative materials: a review," Australian Dental Journal, vol. 49, no. 3, pp. 112-21; quiz 154, Sep, 2004.

[2] J. W. Nicholson, "Chemistry of glass-ionomer cements: a review," Biomaterials, vol. 19, no. 6, pp. 485-494, Mar, 1998.

[3] T. P. Croll, and J. Nicholson, "Glass ionomer cements in pediatric dentistry: review of the literature," Pediatric dentistry, vol. 24, no. 5, pp. 423-429, Sep-Oct, 2002.

[4] S. K. Sidhu, and J. W. Nicholson, "A Review of Glass-Ionomer Cements for Clinical Dentistry," Journal of Functional Biomaterials, vol. 7, no. 3, Jun 28, 2016

[5] J. W. Nicholson, "Adhesion of glass-ionomer cements to teeth: A review," International Journal of Adhesion and Adhesives, vol. 69, pp. 33-38, 2016.

[6] S. Mokhtari, and A. W. Wren, "Investigating the effect of Copper Addition on $\mathrm{SiO} 2-\mathrm{ZnO}-\mathrm{CaO}-$ SrO-P2O5 Glass Polyalkenoate Cements: Physical, Mechanical and Biological Behavior," Biomedical Glasses, 1,p. 13, 2019.

[7] U. Lohbauer, "Dental Glass Ionomer Cements as Permanent Filling Materials? - Properties, Limitations and Future Trends," Materials, vol. 3, no. 1, pp. 76-96, 2009.

[8] P. V. Hatton, K. Hurrell-Gillingham, and I. M. Brook, "Biocompatibility of glass-ionomer bone cements," Journal of Dentistry, vol. 34, no. 8, pp. 598-601, Sep, 2006.

[9] S. Mokhtari, K. D. Skelly, E. A. Krull, A. Coughlan, N. P. Mellott, Y. Gong, R. Borges, and A. W. Wren, "Copper-containing glass polyalkenoate cements based on $\mathrm{SiO} 2-\mathrm{ZnO}-$ $\mathrm{CaO}-\mathrm{SrO}-\mathrm{P} 2 \mathrm{O} 5$ glasses: glass characterization, physical and antibacterial properties," Journal of Materials Science, vol. 52, no. 15, pp. 8886-8903, 2017.

[10] A. A. Gorustovich, T. Steimetz, R. L. Cabrini, and J. M. Porto Lopez, "Osteoconductivity of strontium-doped bioactive glass particles: a histomorphometric study in rats," Journal of biomedical materials research. Part A, vol. 92, no. 1, pp. 232-7, Jan, 2010.

[11] J. W. Nicholson, and B. Czarnecka, "Review paper: Role of aluminum in glass-ionomer dental cements and its biological effects," Journal of
Biomaterials Applications, vol. 24, no. 4, pp. 293308, Nov, 2009.

[12] A. D. Wilson, and J. W. Nicholson, Acid-base cements: their biomedical and industrial applications: Cambridge University Press, 2005.

[13] D. S. Brauer, E. Gentleman, D. F. Farrar, M. M. Stevens, and R. G. Hill, "Benefits and drawbacks of zinc in glass ionomer bone cements," Biomedical Materials, vol. 6, no. 4, pp. 045007, Aug, 2011.

[14] J. W. Nicholson, J. H. Braybrook, and E. A. Wasson, "The biocompatibility of glasspoly(alkenoate) (Glass-Ionomer) cements: A review," Journal of Biomaterials Science, Polymer Edition, vol. 2, no. 4, pp. 277-285, 1991.

[15] S. G. Griffin, and R. G. Hill, "Influence of glass composition on the properties of glass polyalkenoate cements. Part I: influence of aluminium to silicon ratio," Biomaterials, vol. 20, no. 17, pp. 1579-86, Sep, 1999.

[16] M. Towler, C. Crowley, D. Murphy, and A. M. C. O'Callaghan, "A preliminary study of aluminumfree glass polyalkenoate cement," Journal of Materials Science Letters, vol. 21, pp. 1123-1126, 2002.

[17] S. Mokhtari, E. A. Krull, L. M. Sanders, A. Coughlan, N. P. Mellott, Y. Gong, R. Borges, and A. W. Wren, "Investigating the effect of germanium on the structure of $\mathrm{SiO} 2-\mathrm{ZnO}-\mathrm{CaO}-$ SrO-P2O5 glasses and the subsequent influence on glass polyalkenoate cement formation, solubility and bioactivity," Materials Science and Engineering: C, vol. 103, pp. 109843, 2019.

[18] Y. C. Fredholm, N. Karpukhina, R. V. Law, and R. G. Hill, "Strontium containing bioactive glasses: Glass structure and physical properties," Journal of Non-Crystalline Solids, vol. 356, no. 44, pp. 2546-2551, 2010.

[19] J. Lao, E. Jallot, and J.-M. Nedelec, "StrontiumDelivering Glasses with Enhanced Bioactivity: A New Biomaterial for Antiosteoporotic Applications?," Chemistry of Materials, vol. 20, no. 15, pp. 4969-4973, 2008.

[20] M. O'donnell, P. Candarlioglu, C. Miller, E. Gentleman, and M. Stevens, "Materials characterisation and cytotoxic assessment of strontium-substituted bioactive glasses for bone regeneration," Journal of Materials Chemistry, vol. 20, no. 40, pp. 8934-8941, 2010.

[21] A. 1. J. Leite, A. I. Gonçalves, M. r. T. Rodrigues, M. E. Gomes, and J. o. F. Mano, "StrontiumDoped Bioactive Glass Nanoparticles in Osteogenic Commitment," ACS applied materials \& interfaces, vol. 10, no. 27, pp. 23311-23320, Jul 11,2018

[22] J. Hao, A. Acharya, K. Chen, J. Chou, S. Kasugai, and N. Lang, "Novel bioresorbable strontium hydroxyapatite membrane for guided bone 
regeneration," Clinical oral implants research, vol. 26, no. 1, pp. 1-7, 2015.

[23] H. Tripathi, C. Rath, A. S. Kumar, P. P. Manna, and S. Singh, "Structural, physico-mechanical and in-vitro bioactivity studies on $\mathrm{SiO} 2-\mathrm{CaO}-\mathrm{P} 2 \mathrm{O} 5-$ $\mathrm{SrO}-\mathrm{Al} 2 \mathrm{O} 3$ bioactive glasses," Materials Science and Engineering: C, vol. 94, pp. 279-290, 2019.

[24] International Organization for Standardization 9917, "Dentistry- Dental Water Based Cements, "Geneva, Switzerland. p. CH-11211, 2017.

[25] H. J. Prosser, D. R. Powis, and A. D. Wilson, "Glass-ionomer cements of improved flexural strength," Journal of dental research, vol. 65, no. 2, pp. 146-8, Feb, 1986.

[26] P. V. Hatton, V. R. Kearns, and I. M. Brook, "11 Bone-cement fixation: glass-ionomer cements "
Joint Replacement Technology, pp. 252-263: Woodhead Publishing, 2008.

[27] W. Higgs, P. Lucksanasombool, R. Higgs, and M. Swain, "Evaluating acrylic and glass-ionomer cement strength using the biaxial flexure test," Biomaterials, vol. 22, no. 12, pp. 1583-1590, 2001.

[28] S. Mokhtari, and A. W. Wren, "13 - Bioactive glasses 2: Composite bone void fillers," Bioactive Glasses (Second Edition), H. Ylänen, ed., pp. 365380: Woodhead Publishing, 2018.

[29] L. L. Hench, N. Roki, and M. B. Fenn, "Bioactive glasses: Importance of structure and properties in bone regeneration," Journal of Molecular Structure, vol. 1073, pp. 24-30, 2014.
Publish your research article in AIJR journals-

$\checkmark \quad$ Online Submission and Tracking

$\checkmark \quad$ Peer-Reviewed

$\checkmark \quad$ Rapid decision

$\checkmark \quad$ Immediate Publication after acceptance

$\checkmark \quad$ Articles freely available online

$\checkmark \quad$ Retain full copyright of your article.

Submit your article at journals.aijr.in
Publish your books with AIJR publisher-

$\checkmark \quad$ Publish with ISBN and DOI.

$\checkmark \quad$ Publish Thesis/Dissertation as Monograph.

$\checkmark \quad$ Publish Book Monograph.

$\checkmark \quad$ Publish Edited Volume/ Book.

$\checkmark \quad$ Publish Conference Proceedings

$\checkmark \quad$ Retain full copyright of your books.

Submit your manuscript at books.aijr.org 